\title{
Physicochemical Characterization and Dissolution Enhancement of Bilastine by Solid Dispersion
}

\author{
Sanjeshkumar G. Rathi*, Dhruv B. Chaudhari, Sohansinh S.Vaghela, Kaushik R Kamani \\ Department of Pharmaceutics, Saraswati Institute of Pharmaceutical Sciences, Dhanap. Gandinagar-382355, Gujarat, India. \\ *Corresponding author's E-mail: rathi.sanjesh@gmail.com
}

Received: 03-05-2021; Revised: 22-06-2021; Accepted: 30-06-2021; Published on: 15-07-2021.

\section{ABSTRACT}

The solid dispersions of Bilastine with HPMC, PVP K30 and HPC have been prepared in different weight ratios by using solvent evaporation method. DSC was used to characterize the samples of solid dispersions and pure drug. Drug found compatible with the excipients. The highest improvements in solubility and in-vitro drug release were observed in solid dispersion prepared with HPC (F14) by solvent evaporation method. The increased dissolution rate of drug from solid dispersion may be due to surface tension lowering effect of polymer to the medium and increased wettability and dispersibility of drug. Hence, F14 Solid dispersion with the HPC carrier considered as most satisfactory among all solid dispersions.

Keywords: Solid Dispersion, Bilastine, HPMC, PVP K30.

QUICK RESPONSE CODE $\rightarrow$

DOI:

10.47583/ijpsrr.2021.v69i01.028

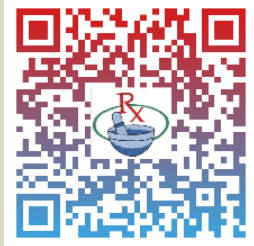

DOI link: http://dx.doi.org/10.47583/ijpsrr.2021.v69i01.028

\section{INTRODUCTION}

olubility is defined here as the concentration of the solute in a solution when equilibrium exists between the pure solute phase and the solution phase. At low concentrations, solubility is difficult to measure analytically, and at high concentrations, solubility is not an issue in the discovery process. Knowledge of the solubility of a drug in water can be critical in formulating products, developing analytical methods, and evaluating drug transport or distribution problems. The approaches presented in this chapter are ideal solution theory, regular solution theory, and the Hansen solubility approach. Of these three, the only one that was developed to describe solutions involving polar species was the Hansen approach. As the reader will discover, however, the Hansen approach is principally based on regular solution theory, which, in turn, was derived from ideal solution theory. Thus, one cannot consider the Hansen solubility approach without some Oral drug delivery is the simplest and easiest way of administering drugs. Because of the greater stability, smaller bulk, accurate dosage and easy production, solid oral dosages forms have many advantages over other types of oral dosage forms. Therefore, most of the new chemical entities (NCE) under development these days are intended to be used as a solid dosage form that originate an effective and reproducible in vivo plasma concentration after oral administration. In fact, most NCEs are poorly water soluble drugs, not well-absorbed after oral administration, which can detract from the drug's inherent efficacy. Moreover, most promising NCEs, despite their high permeability, are generally only absorbed in the upper small intestine, absorption being reduced significantly after the ileum, showing small absorption window. Consequently, if these drugs are not completely released in this gastrointestinal area, they will have a low bioavailability. Therefore, one of the major current challenges of the Pharmaceutical industry is related to strategies that improve the water solubility of drugs. Drug release is a crucial and limiting step for oral drug bioavailability, particularly for drugs with low gastrointestinal solubility and high permeability. By improving the drug release profile of these drugs, it is possible to enhance their bioavailability and reduce side effects. The lack of ability of a drug to go into solution is sometimes a more important limitation to its rate of absorption than its ability to permeate intestinal mucosa. For many drugs that cross the intestinal mucosa easily, the onset of drug levels will be dictated by the time required for the dosage form to release its contents, and for the drug to dissolve. We may define a drug as 'poorly soluble' when its dissolution takes longer than the transit time past its absorptive sites, resulting in incomplete bioavailability. The aqueous solubility of a drug is a prime determinant of its dissolution rate and in the case of poorly soluble drugs (as defined above); the aqueous solubility is usually less than $100 \mu \mathrm{g} / \mathrm{ml}$. A further parameter that is useful for identifying 'poorly soluble' drugs is the dose: solubility ratio of the drug. The dose: solubility ratio can be defined as the volume of gastrointestinal fluids necessary to dissolve the administered dose. When this volume exceeds the volume of fluids available, one may anticipate incomplete bioavailability from solid oral dosage forms.

\section{- $\quad$ Need For Solubility Enhancement 3,4}

Solubility is one of the important parameters to achieve desired concentration of drug in systemic circulation for 
achieving required pharmacological response. Any drug to be absorbed must be present in the form of an aqueous solution at the site of absorption. The drug in the dosage forms is released and dissolves in the surrounding gastrointestinal fluid to form a solution for easy absorption. This process is solubility limited. Once the drug is in the solution form it passes across the membrane of the cell lining the gastrointestinal tract. This process is permeability limited. Then afterwards the drug is absorbed into systemic circulation. In the sense, the oral bioavailability of drug is determined by the extent of drug solubility and permeability. Thus absorption from the GI tract can be limited by a variety of factors most significant contributor being poor aqueous solubility and poor membrane permeability of the drug molecule. The BCS is a scientific framework for classifying a drug substance based on its aqueous solubility and intestinal permeability.

\section{MATERIALS}

Bilastine received as gift sample from Torrent Research Centre, Ahmedabad. HPMC, PVP K30, HPC, Lactose DCL 11, Microcrystalline Cellulose $\mathrm{pH} 102$, Magnesium Stearate and Talc purchased from Balaji Chemicals, Ahmedabad.

\section{METHODS $^{5,6}$}

\section{Pre-formulation Study}

\section{Organoleptic Characteristics}

Colour and odour of drug were characterized and recorded using descriptive terminology.

\section{Melting Point}

Melting point of the API was checked using capillary melting method. The observed melting point was checked with the reference data.

\section{Flow Properties}

\section{Bulk density and tapped density}

Weighed quantity of the powder (W), was carefully poured into the graduated cylinder and the volume $\left(V_{0}\right)$ was measured. After that by tapping 100 times manually, the volume was checked and calculated from below equation.

$$
\begin{gathered}
\text { Bulk density }=\mathrm{W} / \mathrm{V}_{0} \\
\text { Tapped density }=\mathrm{W} / \mathrm{V}_{\mathrm{F}} \\
\text { Compressibility Index }(\mathrm{Cl}) / \text { Carr's index }
\end{gathered}
$$

Compressibility index $(\mathrm{Cl})$ / Carr's index was calculated by using the following formula.

$$
\begin{aligned}
& \% \text { Carr's index }=(\text { Tapped density }- \text { Bulk density } \div \text { Tapped } \\
& \text { density) } \times 100
\end{aligned}
$$

\section{Hausner's ratio (HR)}

Hausner's ratio is a number that is correlated to the flow ability of a powder. It is measured by ratio of tapped density to bulk density.

$$
\text { Hausner's ratio }=(\text { Tapped density } \div \text { Bulk Density })
$$

\section{Angle of repose (AR)}

Angle of repose of powder was determined by the funnel method. Accurately weight powder was taken in the funnel. Height of the funnel was attuned in such a way the angle of the funnel just touched the apex of the powder. Powder blend was allowed to flow through the funnel freely on to the surface. Diameter of the powder cone was measured and angle of repose was calculated using the following equation.

$\operatorname{Tan} \theta=h / r$

Table 1: Formulation table of Bilastine Solid Dispersion

\begin{tabular}{|c|c|c|c|c|c|}
\hline Batch & Bilastine (mg) & HPMC (mg) & PVP K30 (mg) & HPC (mg) & Ratio (Drug: Carrier) \\
\hline F1 & 10 & 5 & - & - & $1: 0.5$ \\
\hline F2 & 10 & 10 & - & - & $1: 1$ \\
\hline F3 & 10 & 15 & - & - & $1: 1.5$ \\
\hline F4 & 10 & 20 & - & - & $1: 2$ \\
\hline F5 & 10 & 25 & - & - & $1: 2.5$ \\
\hline F6 & 10 & - & 5 & - & $1: 0.5$ \\
\hline F7 & 10 & - & 10 & - & $1: 1$ \\
\hline F8 & 10 & - & 15 & - & $1: 1.5$ \\
\hline F9 & 10 & - & 20 & - & $1: 2$ \\
\hline F10 & 10 & - & 25 & - & $1: 2.5$ \\
\hline F11 & 10 & - & - & 5 & $1: 0.5$ \\
\hline F12 & 10 & - & - & 10 & $1: 1$ \\
\hline F13 & 10 & - & - & 15 & $1: 1.5$ \\
\hline F14 & 10 & - & - & 20 & $1: 2$ \\
\hline F15 & 10 & - & - & 25 & $1: 2.5$ \\
\hline
\end{tabular}




\section{Solubility study}

Solubility of Bilastine was observed in different solvents such as water, $0.1 \mathrm{~N} \mathrm{HCl}, 6.8$ phosphate buffer and methanol. Saturated solutions were prepared by adding excess drug to the vehicles and shaking on the shaker for 24 hours under constant vibration. After this period the solutions were filtered, diluted and analyzed by UV Spectrophotometer at $206 \mathrm{~nm}$.

\section{Preparation of Solid Dispersion (SD)}

Solid dispersions of Bilastine were prepared by solvent evaporation methods using different carriers like HPMC, PVP K30 and HPC. Following are the method of preparations.

\section{- Solvent Evaporation Method 7,8}

\section{Procedure}

The drug was dissolved in sufficient quantity of solvent, methanol. To this solution, sufficient amount of carrier was added. This mixture was stirred well and then evaporated in a water bath. This system was dried in a vacuum oven. Kept in an air tight container and stored in desiccators.

\section{Characterization of Solid Dispersions ${ }^{9,10}$}

\section{Percent Practical Yield}

Percentage practical yield were calculated to know about percent yield or efficiency of any method, thus its help in selection of appropriate method of production. Solid

Dispersions were collected and weighed to determine practical yield (PY) from the following equation.

$$
\begin{gathered}
\text { PY }(\%)=\text { Practical Mass (SD) } / \text { Theoretical Mass (Drug + } \\
\text { Carrier) }] \times 100
\end{gathered}
$$

\section{Drug Content}

The solid dispersion equivalent to $20 \mathrm{mg}$ of drug were taken and dissolved separately in $100 \mathrm{ml}$ of $0.1 \mathrm{~N} \mathrm{HCl}$. The solutions were filtered and were further diluted such that the absorbance falls within the range of standard curve. The absorbance of solutions was determined at $206 \mathrm{~nm}$ by UV spectrophotometer.

\section{Solubility study}

To evaluate increase in solubility of Bilastine, after forming optimized formulations saturation solubility measurements were carried out. Known excess of optimized formulations were added to $10 \mathrm{ml}$ of distilled water. Samples were shaken for 24 hours at room temperature in a magnetic stirrer. Samples were then filtered through No. 41 whatman filter paper and the filtrate was suitably diluted and analyzed spectrophotometrically at $206 \mathrm{~nm}$.

\section{FTIR Spectroscopy}

IR spectral analysis of optimized formulations was carried out. Observation was made whether changes in the chemical constitution of drug occurred after combining it with the polymers. The absorption maxima in spectrum were compared with the reference spectrum.

\section{Differential scanning calorimetry}

DSC thermogram of drug and optimized formulations were recorded on the DSC. Samples were sealed in pans and scanned at a heating rate of $10^{\circ} \mathrm{C} \mathrm{min}^{-1}$ over a temperature range of $50-300^{\circ} \mathrm{C}$ under nitrogen gas stream.

\section{Dissolution studies}

Dissolution studies were carried employing USP dissolution apparatus type $\mathrm{II}$, using $900 \mathrm{ml} 0.1 \mathrm{~N} \mathrm{HCl}$ as the dissolution medium at $50 \mathrm{rpm}$ and $37 \pm 0.5^{\circ} \mathrm{C}$. The samples were periodically withdrawn at suitable time intervals 0,5 , $10,15,30,45 \& 60$ minutes and volume replaced with equivalent amount of plain dissolution medium. The samples were filtered and diluted. Absorbance of the resulting solution at $206 \mathrm{~nm}$ using UV-visible spectrophotometer.

\section{Preparation of Tablets}

Tablets of most satisfactory batches of each carriers were prepared by direct compression method. Lactose DCL11 was used as diluent. Microcrystalline cellulose (MCC pH 102) used as filler. Talc used as glidant and magnesium stearate used as a lubricant. Additionally, plain API tablets were also prepared for comparison. All the batches were prepared and evaluated for various tableting parameters.

\section{Evaluation of tablets}

The prepared tablets were evaluated for various parameters like, weight variation, thickness, hardness, friability, drug content and dissolution. The evaluation parameters along with method were described below;

\section{Weight variation test}

Accurately weight 20 tablets individually using electronic balance and calculate the average weight of tablets and comparing the individual tablet weights to the average. The parameter was checked in triplicate and average weight along with the standard deviation recorded.

\section{Thickness}

The digital Vernier caliper was used to check the thickness of the tablets. The parameter was checked in triplicate.

\section{Hardness}

The hardness of the tablets was tested by using Monsanto tester. The parameter was checked in triplicate.

\section{Friability test}

The friability of the tablets was determined using Roche Friabilator. The \% friability calculated based on following formula:

$$
\text { Friability }=([\mathrm{W}-\mathrm{W}] / \mathrm{WO}) * 100
$$

Where, Wo =initial weight of tablet; $\mathrm{W}=$ after test weight of tablet. 


\section{Drug content}

Ten tablets were selected randomly and average weight was calculated. Tablets were crushed in a mortar and accurately weighed amount equivalent to powder was taken from the crushed powder and transferred it in to a $100 \mathrm{ml}$ volumetric flask. $10 \mathrm{ml}$ of $0.1 \mathrm{~N} \mathrm{HCl}$ was added and sonicated for 10 minutes. Then volume was made up to $100 \mathrm{ml}$ with $0.1 \mathrm{~N} \mathrm{HCl}$. The $1 \mathrm{~mL}$ of resultant solution was diluted to $100 \mathrm{~mL}$ with $0.1 \mathrm{~N} \mathrm{HCl}$. The absorbance of above solution was measured in UV spectrophotometer at 206 $\mathrm{nm}$.

\section{RESULTS AND DISCUSSION}

\section{Characterization of Bilastine}

Observations of organoleptic characteristics, flow properties and melting point of Bilastine are shown in below table 2 .

Table 2: Characterization of Bilastine

\begin{tabular}{|c|c|c|c|}
\hline Sr. No. & \multicolumn{2}{|c|}{ Characteristic Properties } & Observation/Result \\
\hline \multirow{2}{*}{1} & \multirow{2}{*}{$\begin{array}{l}\text { Organoleptic } \\
\text { Characteristics }\end{array}$} & Colour & White colour powder \\
\hline & & Odour & Odorless \\
\hline 2 & \multicolumn{2}{|c|}{ Description } & Bilastine is a white colour crystalline powder \\
\hline \multirow{5}{*}{3} & \multirow{5}{*}{ Flow Properties } & Bulk density $(\mathrm{g} / \mathrm{ml})$ & $0.28 \pm 0.03$ \\
\hline & & Tapped density $(\mathrm{g} / \mathrm{ml})$ & $0.39 \pm 0.02$ \\
\hline & & Carr's index (\%) & $28.21 \pm 0.04$ \\
\hline & & Hausner's ratio & $1.39 \pm 0.03$ \\
\hline & & Angle of repose $\left(\vartheta^{\circ}\right)$ & $32 \pm 1^{\circ}$ \\
\hline 4 & \multicolumn{2}{|c|}{ Melting Point } & $203^{\circ} \mathrm{C}$ \\
\hline
\end{tabular}

Based on above API characterization data, it found that the API has a good flow. As the formulation is solid dispersion and the aim is solubility and dissolution enhancement, API flow does not affect the formulation characteristic. Further, the Melting point which observed during Preformulation study was matched with the reference melting point of API. The API was white colour crystalline powder.

\section{Solubility study of Bilastine}

Bilastine solubility was checked in different solvent and buffers. The results were recorded. The comparative graph also shown in below figure 1 . The highest solubility was found in methanol.

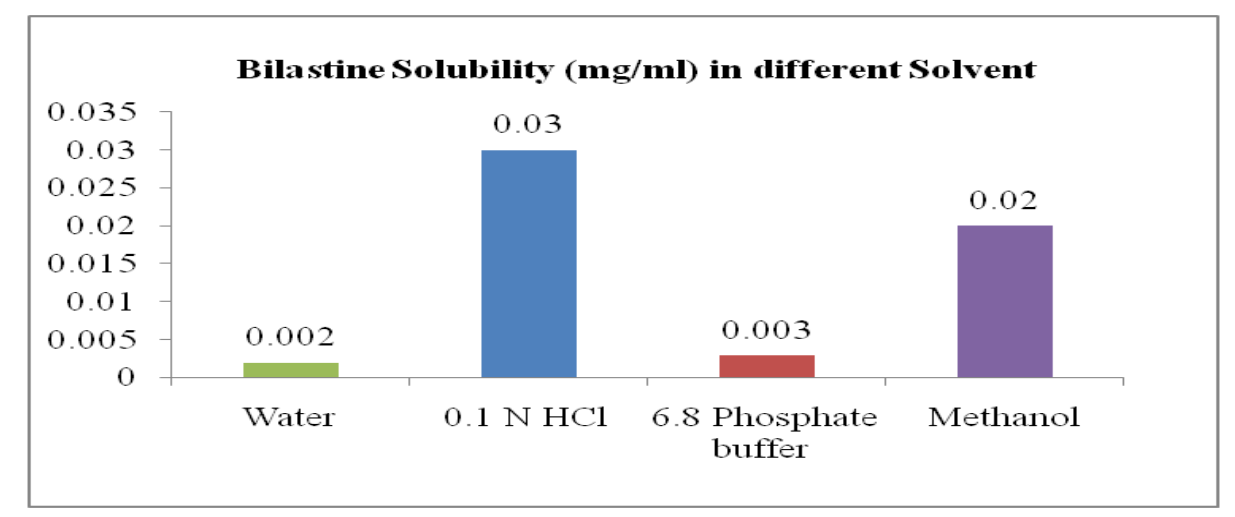

Figure 1: Solubility of Bilastine

Solubility study of API help to identify the solvent for making solid dispersion. Further, selection of buffer media for calibration curve preparation can be identified. Here methanol was selected as solvent for further studies. Calibration curve was prepared in $0.1 \mathrm{~N} \mathrm{HCl}(\mathrm{pH} 1.2)$ and 6.8 phosphate buffer.

\section{Evaluation of Solid Dispersions (SD's)}

Prepared Solid dispersion batches of Bilastine were evaluated for various parameters like, drug content, solubility and $\%$ yield. The drug content of all batches was found between 95 to $99 \%$ which means that the drug was uniformly distributed in formulation. Further, the yield was found low in all batches as the solid dispersion formulation has a less yield. The solubility is the most important parameter for solid dispersions. It was found that the ratio of carrier increases, the solubility of drug was increase. At certain ratio, the solubility found stable and above that ratio solubility not increase significantly. The selection of most satisfactory SD was done bases on solubility parameter. Solid dispersion prepared using HPMC by solvent evaporation method give maximum solubility at 
ratio of $1: 2$. After that the solubility not increases significantly. Solid dispersions prepared by PVP K30 carrier gives maximum solubility in 1:1.5 ratio which is prepared by solvent evaporation method. Solid dispersions prepared by Hydroxypropyl cellulose give maximum solubility in 1:2 ratio. After that increment in drug to carrier ratio not gives significant increase in solubility. The Hydroxypropyl cellulose solid dispersion (F14) gives the highest solubility improvement among all the formulations. The results were recorded in below table 3

Table 3: Results of F1 to F15 formulation

\begin{tabular}{|c|c|c|c|}
\hline Batch & \% Practical Yield $(\mathbf{n}=\mathbf{3})$ & Drug Content $\mathbf{( \% )}(\mathbf{n}=\mathbf{3})$ & Solubility $(\boldsymbol{\mu g} / \mathbf{m l})(\mathbf{n}=\mathbf{3})$ \\
\hline F1 & $77.1 \pm 4.2$ & $98.2 \pm 2.6$ & $3.9 \pm 0.9$ \\
\hline F2 & $81.2 \pm 3.9$ & $97.5 \pm 3.1$ & $8.5 \pm 1.5$ \\
\hline F3 & $80.5 \pm 2.5$ & $98.1 \pm 4.0$ & $14.9 \pm 1.1$ \\
\hline F4 & $81.4 \pm 1.8$ & $97.6 \pm 2.9$ & $19.5 \pm 1.5$ \\
\hline F5 & $84.3 \pm 2.2$ & $98.7 \pm 1.9$ & $19.8 \pm 1.6$ \\
\hline F6 & $80.1 \pm 1.7$ & $98.2 \pm 2.5$ & $5.4 \pm 2.1$ \\
\hline F7 & $77.5 \pm 2.6$ & $97.9 \pm 3.7$ & $12.9 \pm 1.5$ \\
\hline F8 & $81.8 \pm 3.5$ & $97.1 \pm 2.4$ & $28.7 \pm 1.8$ \\
\hline F9 & $82.3 \pm 2.9$ & $97.6 \pm 2.2$ & $28.2 \pm 2.7$ \\
\hline F10 & $84.2 \pm 1.8$ & $97.0 \pm 1.9$ & $27.5 \pm 1.9$ \\
\hline F11 & $81.2 \pm 3.4$ & $98.5 \pm 2.6$ & $12.9 \pm 2.2$ \\
\hline F12 & $83.4 \pm 2.4$ & $97.9 \pm 1.8$ & $29.8 \pm 3.7$ \\
\hline F13 & $82.1 \pm 1.5$ & $97.3 \pm 2.4$ & $40.6 \pm 2.6$ \\
\hline F14 & $84.2 \pm \mathbf{2 . 4}$ & $97.4 \pm 4.1$ & $119.4 \pm 7.1$ \\
\hline F15 & $81.5 \pm 1.4$ & $97.1 \pm 2.2$ & $115.2 \pm 8.6$ \\
\hline Pure API & - & - & $2.0 \pm 1.5$ \\
\hline
\end{tabular}

\section{Characterization of Solid Dispersions}

\section{Characterization of Solid Dispersions by Differential scanning calorimetry}

The solid dispersion DSC thermogram shows reduction in intensity of the peak as compared to pure drug. The sharp peak of pure drug was not observed in solid dispersion, which indicates that the Bilastine was molecularly dispersed and in amorphous form. This change indicates that the dehydration of pure drug and change in the particle size giving more amorphous type of the product this may help in cleaving the solubility of drug. These shifting of peaks are due to the above experimental reason but not to interaction.

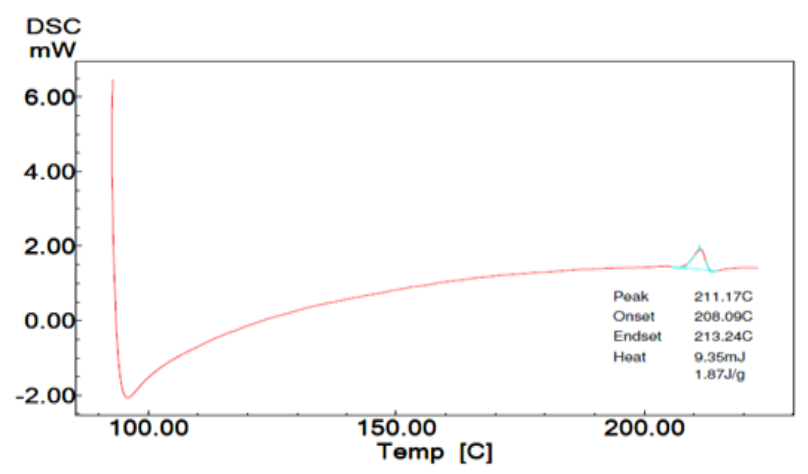

Figure 2: DSC Thermogram of Pure Drug

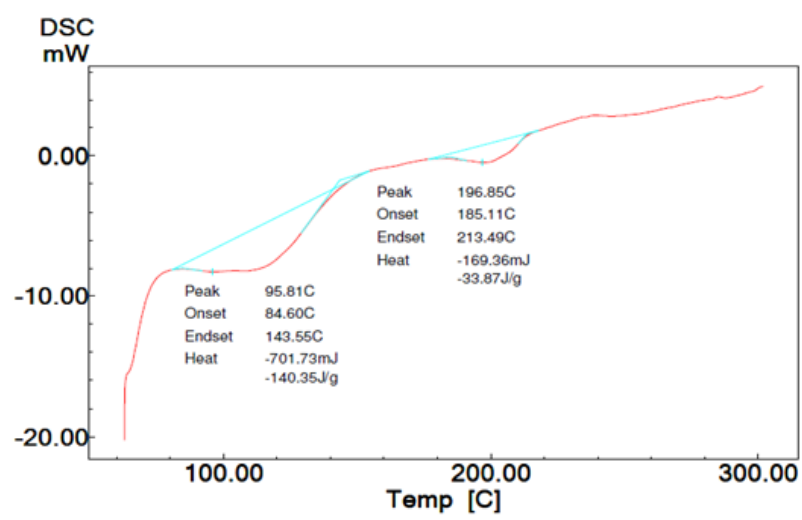

Figure 3: DSC Thermogram of Solid Dispersion of Bilastine

\section{Evaluation of Solid Dispersions}

Optimized solid dispersion formulation of each carrier was evaluated for various parameters. Drug content data found satisfactory. The results were recorded below in table 4 .

Table 4: Evaluation of solid dispersions

\begin{tabular}{|c|c|}
\hline Formulation & Drug Content $(\%)(\mathbf{n}=\mathbf{3})$ \\
\hline API & $99.1 \pm 2.5$ \\
\hline F4 & $98.7 \pm 1.7$ \\
\hline F8 & $99.5 \pm 1.5$ \\
\hline F14 & $99.2 \pm 2.2$ \\
\hline
\end{tabular}


Drug release study of all optimized solid dispersions was performed and data listed in below table 5 . Based on results, it can be observed that the pure API have very slow-release pattern. Further, the SD have faster dissolution profile as compared to the pure API . HPC based solid dispersion tablets gives faster drug release as compared to all tablets. It gives more than $90 \%$ drug release within 60 mins.

Table 5: Dissolution of Solid Dispersions

\begin{tabular}{|c|c|c|c|c|c|c|}
\hline \multicolumn{7}{|c|}{ \% Drug release in min } \\
\hline Batch & $\mathbf{5}$ & $\mathbf{1 0}$ & $\mathbf{1 5}$ & $\mathbf{3 0}$ & $\mathbf{4 5}$ & $\mathbf{6 0}$ \\
\hline API & $5.9 \pm 2.1$ & $11.3 \pm 2.8$ & $17.8 \pm 2.5$ & $32.5 \pm 2.1$ & $47.5 \pm 3.8$ & $58.7 \pm 2.4$ \\
\hline F4 & $14.9 \pm 3.6$ & $29.5 \pm 3.1$ & $41.5 \pm 2.4$ & $70.6 \pm 1.9$ & $78.3 \pm 2.6$ & $82.1 \pm 1.9$ \\
\hline F8 & $18.7 \pm 3.9$ & $35.9 \pm 2.8$ & $46.8 \pm 2.0$ & $74.3 \pm 1.6$ & $80.6 \pm 1.5$ & $85.3 \pm 1.7$ \\
\hline F14 & $\mathbf{2 6 . 2} \pm \mathbf{4 . 1}$ & $\mathbf{4 9 . 5} \pm \mathbf{3 . 4}$ & $\mathbf{6 7 . 1} \pm \mathbf{3 . 1}$ & $\mathbf{8 2 . 9} \pm \mathbf{2 . 0}$ & $\mathbf{8 8 . 7} \pm \mathbf{2 . 3}$ & $\mathbf{9 3 . 1} \pm \mathbf{2 . 5}$ \\
\hline
\end{tabular}

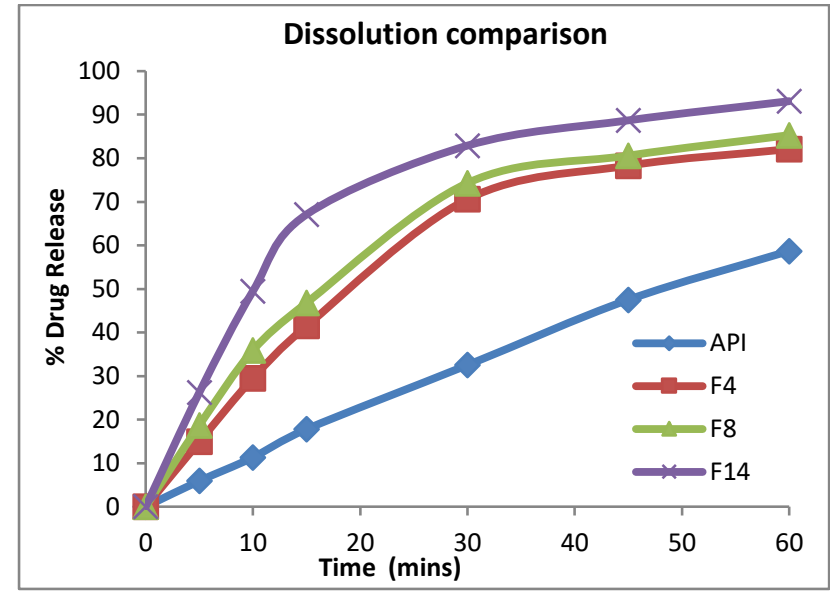

Figure 4: Dissolution comparisons of solid dispersion

\section{Evaluation of Solid Dispersion Tablets}

Tablets of optimized solid dispersion formulation were prepared and evaluated for various tableting parameters. Weight variation of all batches found well within acceptable range. Thickness and hardness found uniform in all batches. Friability found below $1 \%$ in all formulations. Drug content data found satisfactory. The disintegration time found within 60 secs. The results were recorded below.

Table 6: Evaluations of Solid Dispersion Tablets

\begin{tabular}{|c|c|c|} 
Formulation & $\begin{array}{c}\text { Drug Content (\%) } \\
(\mathbf{n}=\mathbf{3})\end{array}$ & $\begin{array}{c}\text { Disintegration } \\
\text { time }(\mathbf{s e c})(\mathbf{n}=\mathbf{3})\end{array}$ \\
\hline API T & $99.1 \pm 2.5$ & $49.2 \pm 2$ \\
\hline F4T & $98.7 \pm 1.7$ & $51 \pm 6$ \\
\hline F8T & $99.5 \pm 1.5$ & $46 \pm 9$ \\
\hline F14T & $99.2 \pm 2.2$ & $55 \pm 3$ \\
\hline
\end{tabular}

Drug release study of all prepared tablets was performed and data listed in below table. Based on results, it can be observed that the pure API tablets have very slow-release pattern. Further, the SD tablets have faster dissolution profile as compared to the pure API tablets. HPC based solid dispersion tablets gives faster drug release as compared to all tablets. It gives more than $90 \%$ drug release within 60 mins.

Table 7: Evaluations of Solid Dispersion Tablets

\begin{tabular}{|c|c|c|c|c|c|c|}
\hline \multicolumn{7}{|c|}{ \% Drug Release } \\
\hline Batch & $\mathbf{5}$ & $\mathbf{1 0}$ & $\mathbf{1 5}$ & $\mathbf{3 0}$ & $\mathbf{4 5}$ & $\mathbf{6 0}$ \\
\hline APIT & $5.9 \pm 2.1$ & $11.3 \pm 2.8$ & $17.8 \pm 2.5$ & $32.5 \pm 2.1$ & $47.5 \pm 3.8$ & $58.7 \pm 2.4$ \\
\hline F4T & $14.9 \pm 3.6$ & $29.5 \pm 3.1$ & $41.5 \pm 2.4$ & $70.6 \pm 1.9$ & $78.3 \pm 2.6$ & $82.1 \pm 1.9$ \\
\hline F8T & $26.2 \pm 4.1$ & $49.5 \pm 3.4$ & $67.1 \pm 3.1$ & $82.9 \pm 2.0$ & $88.7 \pm 2.3$ & $93.1 \pm 2.5$ \\
\hline F14T & $18.7 \pm 3.9$ & $35.9 \pm 2.8$ & $46.8 \pm 2.0$ & $74.3 \pm 1.6$ & $80.6 \pm 1.5$ & $85.3 \pm 1.7$ \\
\hline
\end{tabular}

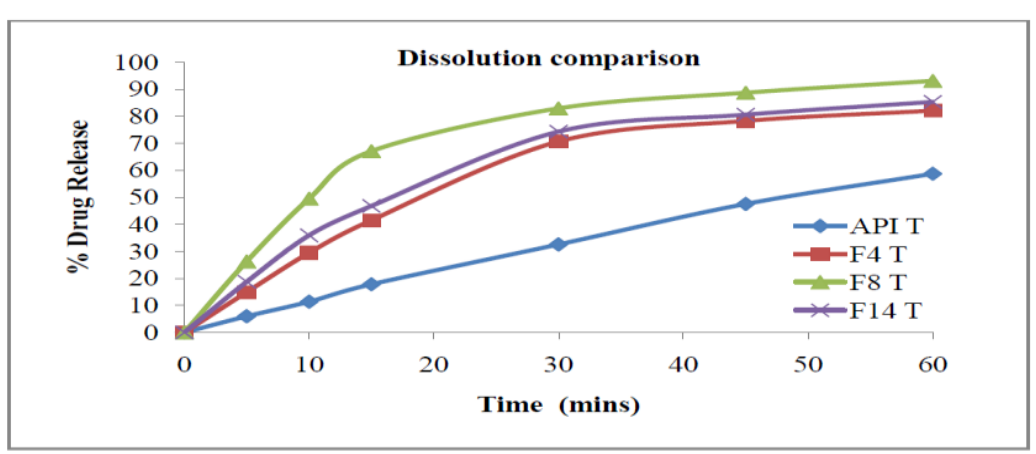

Figure 5: Dissolution comparisons of solid dispersion tablets 


\section{Stability Study}

Stability study of most satisfactory batch tablets (F14T) performed for 1 month. Sample withdrawal after 1 month; it showed no change in in-vitro drug release profile. Results of stability study do not show any remarkable change in the release profile of the tablet after the stability. In stability study after one moth observation no major changes were found.

\section{Statistical Analysis}

Statistical analysis of the drug release data of pure drug and final formulation tablets was done. The MDT, DE and $\mathrm{f} 2$ value comparison was done and the same was given below 8 .

Table 8: Statistical Analysis

\begin{tabular}{|c|c|c|c|}
\hline Batches & $\begin{array}{c}\text { DE } \\
\text { (Dissolution Efficiency) }\end{array}$ & MDT(min) & $f 2$ \\
\hline API T & 4.12 & 17.90 & - \\
\hline F4 T & 0.25 & 1.52 & 42.6 \\
\hline F8 T & 0.22 & 0.96 & 36.8 \\
\hline F14 T & 0.16 & 0.76 & 24.5 \\
\hline
\end{tabular}

From the above results, it's concluded that the Dissolution efficiency vaule is lowest in the F14T Batch. Further, the MDT value also found lower side in F14 batch. For F2 value, dis-similarity observed as compared to other batches. This is due to good drug release profile as compared to pure drug.

\section{CONCLUSION}

The solid dispersions of Bilastine with HPMC, PVP K30 and HPC have been prepared in different weight ratios by using solvent evaporation method. DSC was used to characterize the samples of solid dispersions and pure drug. Drug found compatible with the excipients. The highest improvements in solubility and in-vitro drug release were observed in solid dispersion prepared with HPC (F14) by solvent evaporation method. The increased dissolution rate of drug from solid dispersion may be due to surface tension lowering effect of polymer to the medium and increased wettability and dispersibility of drug. Hence, F14 Solid dispersion with the HPC carrier considered as most satisfactory among all solid dispersions.

\section{REFERENCES}

1. Sandip RP, Shashikant DB. Solubility enhancement (Solid Dispersions) novel boon to increase bioavailability". Journal of Drug Delivery Therapeutics. 2019; 9(2): 583-590.

2. Amol SD, Kundan JT, Vijay RM. Solubility Enhancement Techniques for Poorly Water-Soluble Drugs". Int J Pharm Sci Nanotech. 2017; 10(3): 3701-10.

3. Phuong T, Yong C, Dong-Hyun K, Sang-Eun J-KK, Jeong-Sook P. Overview of the Manufacturing Methods of Solid Dispersion Technology for Improving the Solubility of Poorly Water-Soluble Drugs and Application to Anticancer Drugs". Pharmaceutics. 2019; 11(3): 132.

4. Singh N, Sarangi M. Solid dispersion - A novel approach for enhancement of bioavailability of poorly soluble drugs in oral drug delivery system". Glob j pharmaceu sci. 2017; 3(2): 5556-80.

5. Wlodarski K, Zhang F, Liu T, Sawicki W, Kipping T. Synergistic effect of polyvinyl alcohol and copovidone in itraconazole amorphous solid dispersions. Pharm Res [Internet]. 2018; 35(1): $16 . \quad$ Available from: http://dx.doi.org/10.1007/s11095-017-2313-1

6. Jermain SV, Brough C, Williams RO III. Amorphous solid dispersions and nanocrystal technologies for poorly watersoluble drug delivery - An update. Int J Pharm. 2018; 535(12): 379-92.

7. GeninaN,Hadi B,LobmannK, "Hot melt extrusion as solventFree technique for a continuous manufacturing of drugLoaded mesoporous silica. " J Pharm Sci. 2018; 107: 149155.

8. Yu D, Li J, Williams G. Zhao M, “Electrospun amorphous solid dispersions of poorly water-soluble drugs: A review. "J Control Release. 2018; 292: 91-110.

9. Obaidat R, Tashtoush B, Awad A, Al Bustami R. Using supercritical fluid technology (SFT) in preparation of Tacrolimus SDs. "AAPS PharmSciTech. 2017, 18(2): 481-93.

10. Setyawan D, Setiawardani F, Amrullah Z, Sari R. PEG 8000 increases solubility and dissolution rate of quercetin in solid dispersion system. "Marmara Pharm J, 2018; 22: 259-66.

Source of Support: The author(s) received no financial support for the research, authorship, and/or publication of this article.

Conflict of Interest: The author(s) declared no potential conflicts of interest with respect to the research, authorship, and/or publication of this article.

For any question relates to this article, please reach us at: editor@globalresearchonline.net New manuscripts for publication can be submitted at: submit@globalresearchonline.net and submit_ijpsrr@rediffmail.com 